\title{
Fe-Zr (Iron-Zirconium)
}

\section{H. Okamoto}

\section{Erratum to: Journal of Phase Equilibria and Diffusion (2006) 27(5):543-544 \\ DOI 10.1007/BF02669163}

In Vol. 27, Issue 5, p. 543-544 of the "Fe-Zr (IronZirconium) Review" by H. Okamoto, Fig. 1 and Fig. 2 were, in error, transposed, as well as the conclusion in the review incorrectly stated. The sentence "The most significant difference from all the other diagrams quoted above is the absence of $\beta \mathrm{Fe}_{2} \mathrm{Zr}$ and the presence of $\mathrm{Fe}_{23} \mathrm{Zr}_{6}$." should be revised to read "The most significant difference from all the other diagrams quoted above is the presence of $\beta \mathrm{Fe}_{2} \mathrm{Zr}$ and the absence of $\mathrm{Fe}_{23} \mathrm{Zr}_{6}$.", and the figures should be interchanged. The printed captions to these figures, however, should remain as is printed on the original pages. 